\section{International Scientific Journal Theoretical \& Applied Science}

\author{
p-ISSN: 2308-4944 (print) e-ISSN: 2409-0085 (online) \\ Year: 2017 Issue: 08 Volume: 52
}

Published: $30.08 .2017 \quad$ http://T-Science.org
Sergey Alexandrovich Mishchik Associate Professor, Candidate of Pedagogical Science, Academician of International Academy TAS, Assistant professor Department of Physics, State Maritime University Admiral Ushakov, Russia, sergei_mishik@mail.ru

SECTION 21. Pedagogy. Psychology. Innovation in Education

\title{
SYSTEMIC PROBLEMS ELECTRICITY SEA AND OCEAN OF APPLIED PHYSICS MARITIME FLOT OF PEDAGOGOMETRIC ANALYSIS
}

Abstract: The basic principles of the system of problems electricity sea and ocean in applied physics Navy pedagogometric analysis of the formation of mathematical models of learning activities about the nature of achieving the criteria of life, cycling, systemness and phasing, which form a basic cell of the educational space, as well as prima nenie twelve pointed star Ertsgammy relatively presentation ertsgamming principle which determines the foundations pedagogometric through forming substantive methods of hyper-space professional life, psychological and educational activity theory, psycho-pedagogical system analysis and the theory of the formation of mental actions.

Key words: pedagogometric, vital activity, cyclicity, system, phase, star Erzgammy, electricity sea and ocean, applied physics, marine fleet.

Language: Russian

Citation: Mishchik SA (2017) SYSTEMIC PROBLEMS ELECTRICITY SEA AND OCEAN OF APPLIED PHYSICS MARITIME FLOT OF PEDAGOGOMETRIC ANALYSIS. ISJ Theoretical \& Applied Science, 08 (52): 102-107.

Soi: http://s-o-i.org/1.1/TAS-08-52-16 Doi: crostsef https://dx.doi.org/10.15863/TAS.2017.08.52.16

\section{УДК 372.851}

\section{СИСТЕМНЫЕ ЗАДАЧИ ЭЛЕКТРИЧЕСТВА МОРЯ И ОКЕАНА ПРИКЛАДНОЙ ФИЗИКИ МОРСКОГО ФЛОТА ПЕДАГОГОМЕТРИЧЕСКОГО АНАЛИЗА}

Аннотация: Рассмотрены основные принцииы построения системных задач электричества моря и океана прикладной физики морского флота педагогометрического анализа при формировании математических моделей учебной деятельности относительно характера достижения критериев жизнедеятельности, иикличности, системности и этапности, которые образуют базисную ячейку образовательного пространства, а также применение двенадиати конечной звезды Эригаммы относительно представления принијипа эригаммности, который определит основы педагогометрики через формообразование предметными методами гиперпространства профессиональной жизнедеятельности, психолого-педагогической теории деятельности, психолого-педагогического системного анализа и теории формирования умственных действий.

Ключевые слова: педагогометрика, жизнедеятельность, ичиклчность, системность, этапность, звезда Эригаммы, электричество моря и океана, прикладная физика, морской флот.

\section{Introduction}

Формирование системных задач электричества моря и океана прикладной физики морского флота педагогометрического анализа ориентируется на реализацию общей задачи педагогометрики математических моделей учебной деятельности на основе базисных представлений методологии педагогометрического анализа, выражающего особенности структуры и формы жизнедеятельности, цикличности, системности и этапности. В процессе педагогометрического анализа формируется базисная ячейка образовательного пространства, которая выражает принцип эрцгаммности через всеобщую структуру двенадцати конечной звезды Эрцгаммы. Реализованнная зависимость устанавливает основы педагогометрики через 
представление

предметных м методов

$\begin{array}{lr}\text { гиперпространства } & \text { профессиональной } \\ \text { жизнедеятельности, } & \text { психолого-педагогической }\end{array}$ теории деятельности, психолого-педагогического системного анализа и теории формирования умственных действий $[1,2,3]$.

Полученные условия подготовки инновационных широкопрофильных специалистов направлены на совершенствование базы предметных прикладных профессиональных задач электричества моря и океана прикладной физики морского флота педагогометрического анализа, через целостную профессиональную деятельность на морском флоте. Формирование математических моделей учебнопрофессиональной деятельности специалистов инновационного мышления связываются с: базисной звездой Эрцгаммы гиперпространства жизнедеятельности (Е1); базисным целостносистемным циклом жизнедеятельности (Е2); базисной звездой Эрцгаммы системного анализа (E3); базисным проявлением двенадцати этапов и форм познавательного гиперпространства жизнедеятельности относительно образовательного процесса (E4) [4,5,6].

Проектирование системных задач электричества моря и океана прикладной физики морского флота педагогометрического анализа и адаптивной базы предметных педагогометрических моделей эрцгаммного анализа образовательных объектов с признаком базисно-нормативной эрцгаммности, отражают их обобщённые структуры. В данном случае реализуется собственная функция психологоматематического представления профессионально-значимых объектов системных задач электричества моря и океана прикладной физики морского флота педагогометрического анализа через единство признаков смыслообразования учебно-профессионального действия, его принятия, ориентировочноисполнительно-контрольных признаков и прогноза совершенствования анализа объектов педагогометрческого содержания $[7,8,9]$.

\section{Materials and Methods}

Системные задачи электричества моря и океана прикладной физики морского флота педагогометрического анализа отражают целостно-системное моделирование основных элементов транспортных объектов. При этом возникает ориентация на единство базисных характеристик предметных и исполнительных условий относительно предмета содержания и способа его реализации через представление базисной ячейки образовательного пространства, которая отражает принцип эрцгаммности адекватного структуре двенадцати конечной звезды Эрцгаммы. Рассматриваются: плотность тока смещения в атмосфере океана; максимальная удельная элек-тропроводность области Е ионосферы; напряженность поля, создаваемого биполярным грозовым облаком; плотность тока проводимости зимой в акватории моря на морском флоте [10,11].

В процессе решения системных задач электричества моря и океана прикладной физики морского флота необходимо применять основные положения теории деятельности, системного анализа и теории формирования интеллекта через построение математических моделей учебнопрофессиональной активности отражающей структуру: базисной звездой Эрцгаммы гиперпространства жизнедеятельности (E1); базисного целостно-системного циклом жизнедеятельности $(\mathrm{E} 2)$; базисной звездой Эрцгаммы системного анализа (Е3); базисного проявления двенадцати этапов и форм познавательного гиперпространства жизнедеятельности относительно образовательного процесса (E4).

Системный анализ предполагает выполнение последовательности системных аналитических действий: выделить объект анализа -задачу электричества моря и океана прикладной физики морского флота (ЗЭМОПФМФ) как систему; установить порождающую среду ЗЭМОПФМФ; определить уровни анализа ЗЭМОПФМФ; представить целостные свойства ЗЭМОПФМФ отно-сительно пространственных, и временных характеристик и их комбинаций; выделить структуру уровня анализа ЗЭМОПФМФ; установить структурные элементы уровня анализа ЗЭМОПФМФ; определить системообразующие связи данного уровня анализа ЗЭМОПФМФ; представить межуровневые связи анализа ЗЭМОПФМФ; выделить форму организации ЗЭМОПФМФ; установить системные свойства и поведение ЗЭМОПФМФ.

\section{Задача 1}

Вычислить плотность тока смещения в атмосфере океана, если за $t=10$ мин электрическое поле изменилось от $\boldsymbol{E}_{\boldsymbol{l}}=76 \mathrm{~B} / \mathrm{M}$ до $\boldsymbol{E}_{2}=198$ В $/$ м. Сравнить с типичным значением плотности тока проводимости.

$$
\text { Ответ: } J_{c m}=1,78 \cdot 10^{-12} \mathrm{~A} / \mathrm{M}^{2} \text {. }
$$

\section{Задача 2}

Определить максимальную удельную электропроводность области Е ионосферы днем, если критическая частота для этой области $\boldsymbol{v}=$ $4,82 \cdot 10^{6}$ Гц, а число столкновений электронов составляет $\boldsymbol{N}=10^{5} \mathrm{c}^{-1}$. Во сколько раз удельная электропроводность в области Е больше, чем у поверхности Земли, где она равна в среднем $\lambda=$ $2,2 \cdot 10^{-14} \mathrm{CM} / \mathrm{M}$ ? 
Ответ: $\lambda_{\max }=1,22 \cdot 10^{-14} \mathrm{CM} / \mathbf{M} ; k=\mathbf{5 , 5} \cdot 10^{7}$ pa3.

\section{Задача 3}

Тяжелый атмосферный ион массой $\boldsymbol{m}=5 \cdot 10^{-}$ $19 \Gamma$ находится в вертикальном электрическом поле над морем с напряженностью $\boldsymbol{E}=120 \mathrm{~B} /$ м. В каком соотношении находятся сила тяжести иона и кулоновская сила, действующая на ион со стороны электрического поля?

Ответ: $m g / F_{k}=1: 4000$.

\section{Задача 4}

Какой должна быть интенсивность ионизации над поверхностью океана, чтобы обеспечить постоянную концентрацию легких ионов обеих знаков, равную $\boldsymbol{n}=500 \mathrm{~cm}^{-3}$ ? Прилипанием ионов к нейтральным частицам пренебречь.

Ответ: $n / t=0,35 \mathrm{~cm}^{-3} \cdot \mathrm{c}^{-1}$.

\section{Задача 5}

Вычислить напряженность поля, создаваемого биполярным грозовым облаком $\mathbf{C b}$ у поверхности океана, под облаком и на расстоянии $\boldsymbol{r}=10$ км. Центр тяжести нижнего отрицательного заряда (-20 Кл) находится на высоте 3 км, центр тяжести верхнего положительного заряда ( + 20 Кл) - на высоте 7 км. Вычислить напряженности, создаваемые отдельно положительным (а) и отрицательным (б) зарядами, а также суммарную напряженность (B). $130 \mathrm{~B} / \mathrm{M}$;

Ответ: а) 150 В/м и 0,2 В/м; б) 40000 В/м и в) 40150 В/м и 130,2 В/м.

\section{Задача 6}

Вычислить энергию электрического поля нижнего 100-метрового слоя атмосферы над поверхностью океана, приняв среднюю напряженность равной $100 \mathrm{~B} / \mathrm{M}$. Сравнить эту энергию с кинетической энергией, атмосферы, составляющей $4 \cdot 10^{20}$ Дж.

Ответ: $2,3 \cdot 10^{9}$ Дж.

\section{Задача 7}

Определить величину электрического заряда, который индуцируется на поверхности паруса яхты. Площадь поверхности паруса равна $17 \mathrm{~m}^{2}$. Напряженность электрического поля атмосферы над морем $200 \mathrm{~B} / \mathrm{M}$.

Ответ: $3 \cdot 10^{-8}$ Кл.

\section{Задача 8}

Определить плотность тока проводимости зимой в акватории Балтийского моря, если среднее значение напряженности поля у поверхности моря равно $250 \mathrm{~B} / \mathrm{M}$, а проводимость атмосферного воздуха $1,1 \cdot 10^{-14} \quad \mathrm{OM}^{-1} \cdot \mathrm{M}^{-1}$. Электричество какого знака доставляет земной поверхности ток проводимости?

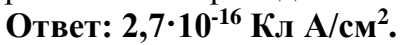

\section{Задача 9}

При разряде молнии за 0,2 с напряженность электрического поля над поверхностью моря изменилась от - 600 до +15000 В/м. Определить ток смещения, который возникнет на металлической крыше судовой надстройки площадью $40 \mathrm{~m}^{2}$ ?

Ответ: $2,76 \cdot 10^{-5} \mathrm{~A}$.

\section{Задача 10}

Определить плотности горизонтальных токов: проводимости и тока адвекции. Среднее значение проводимости атмосферного воздуха над поверхностью моря равно $2 \cdot 10^{-14} \mathrm{OM}^{-1} \cdot \mathrm{M}^{-1}$, вертикальная составляющая напряженности поля 130 В/м, горизонтальная составляющая на 2 порядка меньше вертикальной; скорость ветра 10 м/с и средний объемный заряд у поверхности моря равен $10^{-11}$ Кл/ $\mathrm{M}^{3}$.

Ответ: $2,6 \cdot 10^{-18} \mathrm{~A} / \mathrm{M}^{2} ; 10^{-13} \mathrm{~A} / \mathrm{M}^{2}$.

\section{Задача 11}

Определить время релаксации атмосферы у поверхности океана и на высоте 50 км, если электропроводность воздуха на этих уровнях равна $2 \cdot 10^{-14} \mathrm{OM}^{-1} \cdot \mathrm{M}^{-1}$ и $34 \cdot 10^{-14} \mathrm{OM}^{-1} \cdot \mathrm{M}^{-1}$.

Ответ: 400 c $; 2,4 \cdot 10^{-3}$ c.

\section{Задача 12}

Вертикальный профиль проводимости воздуха над поверхностью океана можно представить экспоненциальным законом $\lambda(\mathbf{z})=\lambda_{0}$ $\exp (\boldsymbol{\alpha z})$, где $\lambda_{\mathrm{o}}=2 \cdot 10^{-14} \mathrm{OM}^{-1} \cdot \mathrm{M}^{-1}, \mathrm{z}$ — высота в километрах, $\boldsymbol{a}=0,4$ км$^{-1}$. Определить удельное сопротивление всей тропосферы. Средняя высота тропосферы 11 километров.

Ответ: $3 \cdot 10^{12}$ Ом $\cdot$ м.

\section{Задача 13}

Определить концентрацию нейтральных ядер атомов атмосферы над поверхностью океана, чтобы обеспечить постоянную концентрацию легких ионов равную $300 \mathrm{~cm}^{-3}$ при интенсивности ионизации $10 \mathrm{~cm}^{-3} \cdot \mathrm{c}^{-1}$ ?

Ответ: $2,74 \cdot 10^{4} \mathrm{~cm}^{-3}$.

\section{Задача 14}

Определить уменьшение числа пар легких ионов в $1 \mathrm{~m}^{3}$ воздуха над поверхностью океана через 5 мин после прекращения ионизации атмосферы в идеально чистом воздухе над океанской поверхностью, если в начальный момент имелось по $5 \cdot 10^{8}$ ионов каждого знака.

Ответ: $97 \cdot 10^{6}$ пар ионов. 


\section{Conclusion}

Условия формирования и развития инновационного широкопрофильного профессионального мышления ориентируется на организацию всестороннего развития педагогометрической эрцгаммности. Выделенные системные задачи электричества моря и океана прикладной физики морского флота педагогометрического анализа устанавливают основные направления развития и совершенствования базы прикладных предметных педагогометрических моделей образовательных объектов относительно педагогометрического математического моделирования учебного процесса. Возникающая образовательная деятельность связывается с процессами совершенствования программируемых математических моделей учебной активности относительно характера достижения критериев жизнедеятельности, цикличности, системности и этапности.

Различные содержательные задачи педагогометрического анализа ориентируются на специальные статистические выборки данных учебного процесса, характеризующих исследуемые образовательные явления и представленных во времени в форме временных рядов. При этом можно одни и те же временные ряды применять для решения разных содержательных педагогометрических задач для анализа параметров субъекта учебной деятельности, методов теоретического и практического анализа, содержательной структуры учебного материала, характера достигнутых результатов, отвечающих ФГОСам соответствуюшего уровня. Это позволяет анализировать содержание и структуру обобщённой учебной деятельности; особенности технологической познавательной деятельности, отражающей структуру системного анализа через обобщённые учебные действия: выделить объект анализа -задачу как систему; установить порождающую среду; определить уровни анализа; представить целостные свойства предмета анализа относительно пространственных, и временных характеристик и их комбинаций; выделить структуру уровня анализа задачи; установить структурные элементы уровня анализа задачи; определить системообразующие связи данного уровня анализа задачи; представить межуровневые связи анализа задачи; выделить форму организации условий задачи; установить системные свойства по параметрам сложности, разнообразия и упорядоченности содержания учебной задачи; представить поведение условий задачи на базисных фазовых состояниях; статической статики, статистической динамики, динамической статики и динамической динамики $[12,13]$.

Общий результат педагогметрического анализ временных рядов отражает динамику развития основных макропедагометрических показателей, характеризующих состояние образовательного процесса как вектора педагогометрического математического моделирования учебной деятельности, которая задаётся установлением критериев эффективного функционирования образовательной системы относительно качества, как многомерной эрцгаммной совокупности. При этом текущее состояние образовательного процесса определяется конечным набором определенных числовых показателей.

В процессе построения многофазного образовательного пространства эрцгаммного типа временной ряд педагогометрических показателей формируется под воздействием набора случайных и неслучайных факторов, которые задают анализ отдельных временных рядов, как результирующих, так и факторных. Это необходимо для формирования адекватной идентификации образовательных моделей, которые строятся по информации об исследуемых процессах - векторные авторегрессии, модели коррекции ошибок, динамические модели с распределенными запаздываниями.

При анализе педагогометрических временных рядов главное внимание связывается с исследованием, описанием и моделированием их структуры. Это позволяет расширить моделирование педагогометрического исследования образовательных процессов. Построенная математическая модель используется для экстраполяции или прогнозирования педагогометрического временного ряда, что повышает качество прогноза развития образовательного процесса, формированию критериев инновационной широкопрофильности при выборе нескольких альтернативных моделей учебной деятельности.

Построение базисной звезды Эрцгаммы гиперпространства жизнедеятельности (E1); базисного целостно-системным цикла жизнедеятельности $(\mathrm{E} 2) ; \quad$ базисной звездой Эрцгаммы системного анализа (Е3); базисного проявления двенадцати этапов и форм познавательного

жизнедеятельности гиперпространства относительно образовательного процесса (Е4) связывается с моделями временных педагогометрических рядов, которые требуют корректировки сезонных эффектов и сглаживания. Построенные модели временных педагогометрических рядов применяются для статистического моделирования длинных рядов 
педагогометрических наблюдений при исследовании больших образовательных систем, для которых временной ряд рассматривается как входная информация об организации эффективной учебно-профессиональной деятельности [14,15].

В связи с наличием ошибок измерения педагогометрических показателей, наличием случайных флуктуаций в образовательных системах, при исследовании временных педагогометрических рядов применяется вероятностно-статистический подход. Наблюдаемый педагогометрический временной ряд понимается как реализация некоторого случайного процесса. При этом предполагается, что временной педагогометрический ряд имеет структуру, отличающую его от последовательности независимых случайных величин и элементы наблюдения не являются набором совершенно независимых числовых значений.

Элементы структуры педагогометрического ряда можно выявить на основании визуального анализа графика педагогометрического ряда. Это относится к таким компонентам ряда, как тренд и циклы. Структура педагогометрического ряда представляется моделью, содержащей небольшое число параметров по сравнению с количеством наблюдений. Это применяют при использовании педагогометрической додели для прогнозирования образовательного пространства. Примерами таких моделей служат модели авторегрессии, скользящего среднего и их комбинации - модели $\operatorname{AR}(\mathrm{p}), \operatorname{MA}(q), \operatorname{ARMA}(p, q)$, $\operatorname{ARIMA}(\mathrm{p}, \mathrm{k}, \mathrm{q})$.

При построении педагогометрических моделей связей в долгосрочной образовательной перспективе важно учитывать факт наличия или отсутствия у анализируемых макропедагогометрических рядов стохастического, недетерминированного тренда. Рассматриваемые педагогометрические ряды относим к классу рядов, стационарных относительно детерминированного тренда, стационарных - TS (trend stationary) ряды, или к классу рядов, имеющих стохастический тренд и приводящихся к стационарному ряду только путем однократного или k-кратного дифференцирования ряда - DS (difference stationary) ряды.

Существенное различие между этими классами педагогометрических рядов выражается в том, что в случае TS (trend stationary) ряда вычитание из ряда соответствующего детерминированного педагогометрического тренда приводит к стационарному педагогометрическому ряду. В случае DS (difference stationary) педагогометрического ряда вычитание детерминированной составляющей ряда оставляет педагогометрический ряд нестационарным из-за наличия у него стохастического образовательного тренда.

Отделение принадлежности рядов классам TS или DS необходимо для адекватного построения долгосрочных регрессионных образовательных моделей, в которых объясняемыми и объясняющими переменными являются макропедагогометрические временные ряды (модели коинтеграции, модели коррекции ошибок, векторные авторегрессии). Построение педагогометрической регрессии DS-ряда на TSряд (с детерминированным трендом) приводит к фиктивным результатам - паразитной (spurious) линейной связи. Паразитная линейная связь возникает и при построении регрессионных образовательных фазовых моделей между двумя статистически независимыми стохастическими образовательными трендами. Если выделяется группа педагогометрических рядов, принадлежащих классу DS-рядов, то между этими рядами возможна коинтеграционная связь, анализ которой позволяет проверять гипотезу эффективности образовательных услуг; устанавливать выполнение на практике теории паритета образовательной необходимости; анализировать выполнение в долгосрочной перспективе уравнения спроса на профессиональные способности.

При наличии коинтеграционной связи между DS-рядами строятся комбинации краткосрочной и долгосрочной динамических регрессионных образовательных моделей в форме модели коррекции ошибок учебной деятельности, что открывает возможность построения на основании подобранной педагогометрической модели краткосрочных и долгосрочных прогнозов развития эрцгаммного образовательного пространства.

Выделенные процессы образуют базисную ячейку образовательного пространства и отражают смысл двенадцати конечной звезды Эрцгаммы относительно представления принципа эрцгаммности. Уставленные структуры определяют основы педагогометрики через формообразование предметными методами гиперпространства профессиональной жизнедеятельности, психолого-педагогической теории деятельности, психолого-педагогического системного анализа и теории формирования умственных действий. Выделенные критерии жизнедеятельности, цикличности, системности и этапности, которые формируют базисную ячейку образовательного пространства, создают условия развития абсолютного инновационного образовательного цикла, отражающего специфическую структуру подготовки широкопрофильно-инновационных специалистов при реализации международных образовательных 
эревнометрического содержания.

\section{References:}

1. Mishchik SA (2014) Pedagogometrika and mathematical modeling educational activity. Materialy Mezhdunarodnoy nauchnoy konferenctsii "Modern mathematics in science" - 30.06.2014. ISJ Theoretical \&Applied Science 6(14): 54-56 Caracas, Venezuela. doi: http://dx.doi.org/10.15863/TAS.2014.06.14.10

2. Mishchik SA (2014) Simulation training activity methods of mathematical logic. Materialy Mezhdunarodnoy nauchnoy konferenctsii "Eurapean Science and Education" - 30.07.2014. ISJ Theoretical \&Applied Science 6(15): 72-74 Marseille, France. doi: http://dx.doi.org/10.15863/TAS.2014.07.15.13

3. Mishchik SA (2014) Mathematical modeling system integrity-cycle of life activity - first goal pedagogometriki. Materialy Mezhdunarodnoy nauchnoy konferenctsii "European Applied Sciences" - 30.08.2014. ISJ Theoretical \&Applied Science 8(16): 77-79. Aix-en-Provence, France. doi: http://dx.doi.org/10.15863/TAS.2014.08.16.13

4. Mishchik SA (2014) Mathematical modeling system integrity-curricular activities - the second problem pedagogometriki. Materialy Mezhdunarodnoy nauchnoy konferenctsii "European Innovation" - 30.09.2014. ISJ Theoretical \&Applied Science 9(17): 126-128 Martigues, France. doi: http://dx.doi.org/10.15863/TAS.2014.09.17.21

5. Mishchik SA (2014) Mathematical modeling holistic-systemic communicative activity - the third task pedagogometriki. Materialy Mezhdunarodnoy nauchnoy konferenctsii "European Scientific Achievements" 30.10.2014. ISJ Theoretical \&Applied Science 10(18): 45-47 Brighton, UK. doi: http://dx.doi.org/10.15863/TAS.2014.10.18.11

6. Mishchik SA (2014) Mathematical modeling integrity - system performance subject - fourth task pedagogometriki. Materialy Mezhdunarodnoy nauchnoy konferenctsii "Eurapean Science and Technology" 30.11.2014. ISJ Theoretical \&Applied Science 11(19): 51-54 Southampton, UK. doi: http://dx.doi.org/10.15863/TAS.2014.11.19.10

7. Mishchik SA (2015) Pedagogometrik - science and academic subject. Materialy Mezhdunarodnoy nauchnoy konferenctsii "European Technology in Science" 28.02.2015. ISJ Theoretical \& Applied Science
02 (22): 103-106 Malmö, Sweden. doi: http://dx.doi.org/10.15863/TAS.2015.02.22.17

8. Zvereva S.V. (1980) Zadachnik po obshhej meteorologii. L.: Gidrometeoizdat 1980 - p.124

9. Tokmazov GV (2014) Matematicheskoe modelirovanie $\mathrm{v}$ uchebno-professional'noy deyatel'nosti. Materialy Mezhdunarodnoy nauchnoy konferentsii «Modern mathematics in science» - 30.06.2014. ISJ Theoretical \& Applied Science 6(14): 44-46. - Caracas, Venezuela. doi: http://dx.doi.org/10.15863/TAS.2014.06.14.8

10. Tokmazov GV (2014) Mathematical modeling research skills in educational activity methods of probability theory. Materialy Mezhdunarodnoy nauchnoy konferenctsii "Eurapean Science and Technology" 30.11.2014. ISJ Theoretical \&Applied Science 11(20): 66-69 Southampton, United Kingdom. doi: http://dx.doi.org/10.15863/TAS.2014.11.19.13

11. Mishhik N.A. (2016) Pravovy'e osnovy' francuzskoj si-stemy' bor'by' s zagryazneniem morya / Nauchny'e issledovaniya: Informaciya, analiz, prognoz [Tekst]: monografiya / [V.E'.Lebedev, A.A.Sviridenko, V.M.Sokolinskij i dr.]; pod obshhej red. prof. O.I.Kirikova - Kniga 51.- Voronezh-Moskva, 2016.

12. Mishchik NA (2014) The practice of french justice article 228 of the UN convention on the law of the sea. Materialy Mezhdunarodnoy nauchnoy konferenctsii "The European Science and Education"- 30.07.2014. ISJ Theoretical \& Applied Science 07 (15): 93-97. - Marseille, France. $\quad$ doi: http://dx.doi.org/10.15863/TAS.2014.07.15.19

13. Mishhik N.A., Antonenko G.A. (2013) Liniya gorizonta kak gradientny'j perepad $\mathrm{V}$ fotograficheskix izmereniyax dlya celej morexodnoj astronomii//E'kspluataciya morskogo transporta. 2013. № 2 (72). Novorossijsk, p. 23-28.

14. Mishhik N.A. (2000) Optimizaciya metodov morexodnoj astronomii [Tekst]: avto-ref.dis. ... kand. tex. nauk: 05.22.16 / N.A.Mishhik. Novorossijsk, 2000. $-24 \mathrm{p}$.

15. Mishhik N.A. (2000) Optimizaciya metodov morexodnoj astronomii [Tekst]: dis. ... kand. tex. nauk: 05.22.16 / N.A.Mishhik. Novorossijsk, 2000. -188 p. 